\title{
New Potential of E-learning by Re-utilizing Open Content Online
}

\section{TED NOTE: English Learning System as an Auto-assignment Generator}

\author{
Ai Nakajima and Kiyoshi Tomimatsu \\ Graduate school of Design, Kyushu University \\ kamirazio@gmail.com, tomimatu@design.kyushu-u.ac.jp
}

\begin{abstract}
We propose an English learning system "TED NOTE," which automatically generates language training game by re-utilizing open content online. As a first prototype, we use Creative Commons licensed content; presentation video and subtitles; from TED.com as educational materials. In this paper, first, we focused on an educational potential of open content online and researched related projects, which apply the concept of the free culture movement for educational uses. In the second half, we describe the design process of TED NOE as a case study. We illustrate the way to re-use and reassemble open contents into the new use technically for providing significant learning experiences in TED NOTE.
\end{abstract}

Keywords: Creative Commons, Open Source, Free Culture, Open culture, e-leaning, learning commons, Gamification, Mash up, Semantic web.

\section{Introduction}

Nowadays a vast amount of the open content, e.g., open source, public domain and creative commons content (CC content) is available as information materials online. It has been regarded as a potential resource for derivative creation.

This situation promotes new concept of creative and collaborative culture, which has become known as the "free culture movement [1]." On YouTube, Flickr, Wikipedia and so on, user generated content (UGC) is growing by uploading and editing every moment, which result in enormous amount of data.

Although activities of the movement are deployed in various areas, free culture is especially expected as big potential to improve style of education in the future. It will not merely a change in academic trainings, but also realize lifelong education and equality of educational opportunity for everyone, everywhere [2]. 


\section{Related Study}

\subsection{Basic and Academic Education}

- The Khan Academy

The Khan Academy (www.khanacademy.org) is the most-used educational streaming service on the Internet with the mission of providing a free world-class education to anyone, anywhere [3]. It consists over 3000 of self-paced video lessons, covering everything from basic addition to advanced calculus, physics, chemistry and biology. It has over 1 million unique students per month.

- iTunes U

iTunes $U$ covers advanced education, which offers a variety of video lectures in world-renowned universities, in order for the new role of a university to the global society.

\subsection{Improvement of Digital Divide}

- The OLPC

The OLPC (One Laptop per Child) project is a famous educational challenge, which is engaged by a research group of Tufts University and the MIT Media Lab[4]. OLPC's mission is to empower the world's poorest children through education and free culture. They provide children in developing countries with low-cost, low-power durable laptops with open-source software for self-learning.

- Hole in the wall

The project "Hole in the Wall" by an education researcher Sugata Mitra is the research about self-organizing systems of learning [5]. In an urban slum in New Delhi, the research team installed an Internet-connected PC, and left it there with a hidden camera filming the area. The experiments have shown that, without supervision or formal teaching, children teach themselves and each other through the Internet, if they're motivated by their curiosity and peer interest.

\subsection{Share Idea}

\section{- Open IDEO}

Open IDEO (www.openideo.com) is an online innovation platform for creative thinkers, where they share their inspirations, ideas and opinions to solve problems together.

After a challenge is posted at OpenIDEO.com, the three development phases; inspiration, concepting and evaluation; are put into motion. Community members can contribute on various approaches, e.g., from observations, photos, sketches and 
comments in the form, to business models and snippets of code. Eventually the winning concept goes to final phases "realization."

- TED

TED organizes global conferences devoted to "ideas worth spreading." It invites activists from three worlds: technology, entertainment and design. TED provides the occasion for them to make presentations to the world and it offered the presentation videos for free online, under the Creative Commons license, through TED.com [6].

The TED Global 2012 initiates the concept of "Radical Openness." They mention about the human potential of collaboration and mutual understanding by the ultraconnected world. In fact, after taking open their contents to public, TED became even more famous all over the world. The subtitles of presentation in multiple languages are created in the way of peer production; engaged by worldwide spontaneous volunteers throughout the Internet.

\section{Concept Design and Design Objective}

\subsection{Concept Design}

"How to re-utilize the open content for educational use" is our main concept of this development. In the previous chapter, we surveyed some related projects, which offer free educational service and occasion using the Internet. But each of them covers all of the process by themselves; from creating open contents to distribute them and manage them. There are few challenges, which try to re-use open content online and convert them into other, educational use.

Basically, creating content itself require a lot of time and effort. On the other hand, as we mentioned in the introduction, a volume of open contents are growing by the way of UGC every second on the Internet. Relaying on this circumstance, we propose the new approaches to designers and engineers; the way to re-design and the way to re-assembly with utilizing open-information resources into other uses. To create new value, we only need to establish efficient architecture, which customizes information resources.

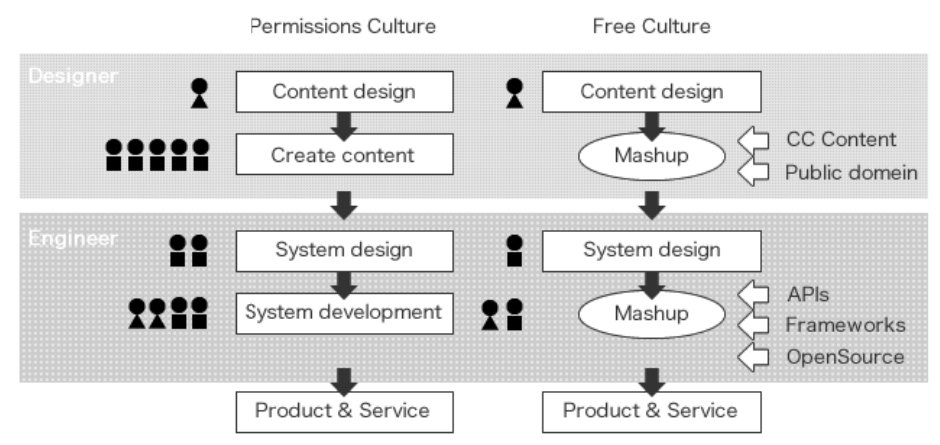

Fig. 1. Difference in development performance 


\subsection{Design Objective}

Whereas it had been difficult to get articles written in foreign languages previously, it now became extremely easy to access them thanks to the Internet. Among the foreign language learners, using the Internet for daily practicing has been one of the popular ways to study them.

But even though the situation gets better, the studying foreign languages by themselves without any introduction are still too much of a bother. So, even now, studying with textbooks is much more popular way. To realize the efficient language learning with the Internet, we need to edit and optimize the data for e-learning style.

We got the idea of the application, which converts raw literal materials in foreign language into the educational material optimized for e-leaning.

We picked English learning up among the foreign language learning as a first design objective for our e-leaning system. Without any doubt, English is the most important and popular language in the world and the core community of free culture is standardized in English as well. Since English is still big barrier for Japanese people, we can gain small benefits from free culture. We need to acquire good English skill to join in the worldwide movement as a necessary precondition.

Also, in terms of digital divide issues, English-language acquisition brings advanced learning opportunity and working chances for the people in developed countries.

\section{Design Process}

In the stage of designing the TED NOTE, we set two design challenges. One is challenge about user experience; how to design the effective and incentive English learning. The other is technical challenge; how to make the best use of open contents as educational material for the e-learning system.

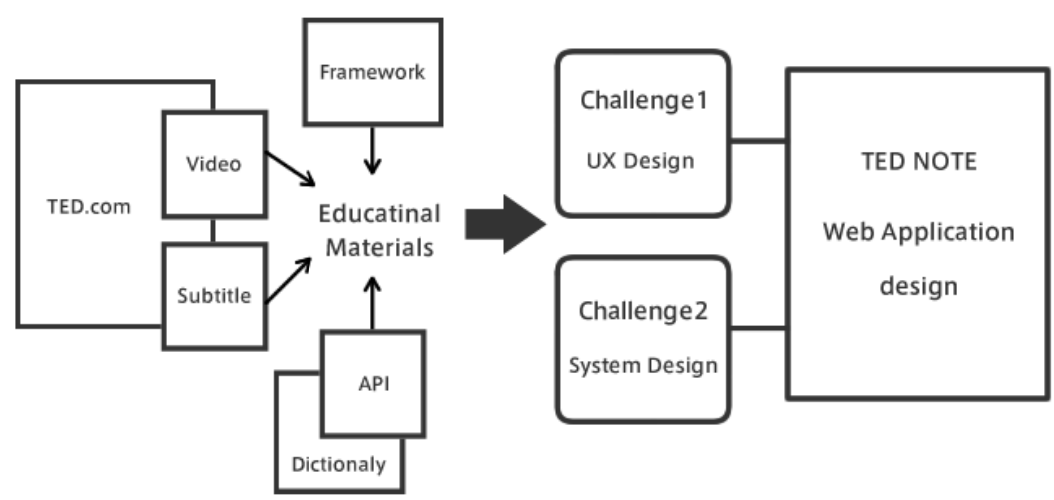

Fig. 2. Design Process 


\subsection{Educational Material}

We chose to use the TED's contents as a main educational material for the application; therefore we named it TED NOTE. The presentation videos are not merely good as English learning itself, but also tell us new exciting knowledge and English expressiveness. Among 1400 TED Talks videos and abundant variety of themes, users can find videos, which meet a specific interest of them. "Switch from studying English to studying WITH English" is a catchword of TED NOTE.

Technically, system architecture of TED.com has favorable style to be re-used. Moreover, TED announced official statement of the expectation for open culture. Also, it provides us the presentation videos and subtitles with the license of creative commons.

\subsection{Design Challenge 1: User Experience Design}

To design the user experiences: effective and incentive learning experiences, we created Personas: target-user models as a method of user-centered design [7].

To create the realistic Personas and to clarify the problems of current English study, we conducted interviews on 10 expected users who all have international experiences; 2 respondents from EU, 1 from central Europe, 1 from Asia and 6 from Japan. We asked their English learning experiences and international experiences. Based on each personal data and their stories, we created 5 Personas. [Table.1]

Table 1. Profile of 5 Personas

\begin{tabular}{|l|l|l|l|l|}
\hline Name & $\begin{array}{l}\text { Male/ } \\
\text { Female }\end{array}$ & $\begin{array}{l}\text { English Level } \\
\text { Country : TOEIC score }\end{array}$ & $\begin{array}{l}\text { Experience } \\
\text { abroad }\end{array}$ & Profile \\
\hline Eric Q & Male & Native English from UK & rich & English teacher in Japan \\
\hline Alex S & Male & non-native form Germany: 670 & few & $\begin{array}{l}\text { University Student in } \\
\text { Kosovo }\end{array}$ \\
\hline Maria L & Female & $\begin{array}{l}\text { non-native form Netherlands: } \\
905\end{array}$ & rich & $\begin{array}{l}\text { Worker in Internet company } \\
\text { in NL }\end{array}$ \\
\hline Emiko S & Female & non-native from Japan: 780 & few & Japanese English Teacher \\
\hline $\begin{array}{l}\text { Takumi } \\
\text { N }\end{array}$ & Male & non-native from Japan: 655 & middle & $\begin{array}{l}\text { Japanese Exchange Student } \\
\text { in Germany }\end{array}$ \\
\hline
\end{tabular}

From the interviews with Japanese respondents, we found a current problem of English study, which doesn't give them the "purpose of learning English." Meanwhile, from the ones from EU, we found key elements to realize incentive English learning. Interests in content are very important to promote the active commitment to self-English study.

We made each story of 5 Personas and we planned the English learning system optimized for each usage. 


\subsection{Design Challenge 2: System Design}

In this section, we report on system design of TED NOTE.

After the advent of Web 2.0, the technical circumstance has been developed as favorable environments, where we can utilize tons of qualified open contents, using the architecture of semantic web and APIs (Application Programming Interface). In this development, we dear to include external web contents and APIs as much as possible, to be a good development-example based on free culture movement.

At the first system-design drawing, we found that the system is required 5 core functions. In the current version, we fulfill three of functions.

1. Loading and conversion function

2. Game function

3. Self-study Management function

4. SNS (Social networking service) function : unfinished

5. User generated assignment editor system (UGC function) : unfinished

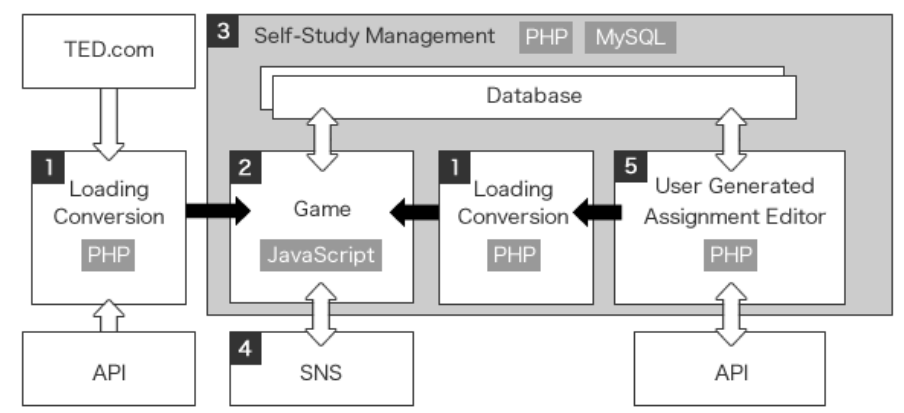

Fig. 3. 5 core functions

We established loading and conversion function in PHP. We built game function in JavaScript. For the dictionary assistant, we use Ajax and APIs offered by WordReference.com and wordnik.com. To monitor the learning effectiveness, we introduced an account system of Facebook API and database in MySQL.

\section{$5 \quad$ User Interface}

In this section, we will discuss the current state of our interface design.

Home Screen: Game Interface. The Home screen of TED NOTE is in game interface; while playing, user has to concentrate to listen to what the presenter said in each statement in the presentation video. When the one statement has played, the video is automatically stopped. User is allowed to repeat the statement over and over till he can catch it.

1. Title \& Link of the presentation

2. Button for "How to Play" \& "Set up" 
3. Presentation Video Monitor

4. Subtitle (Translation)

5. Information \& Score Monitor

6. Timeline Buttons

7. Re-play Button

8. Game Space

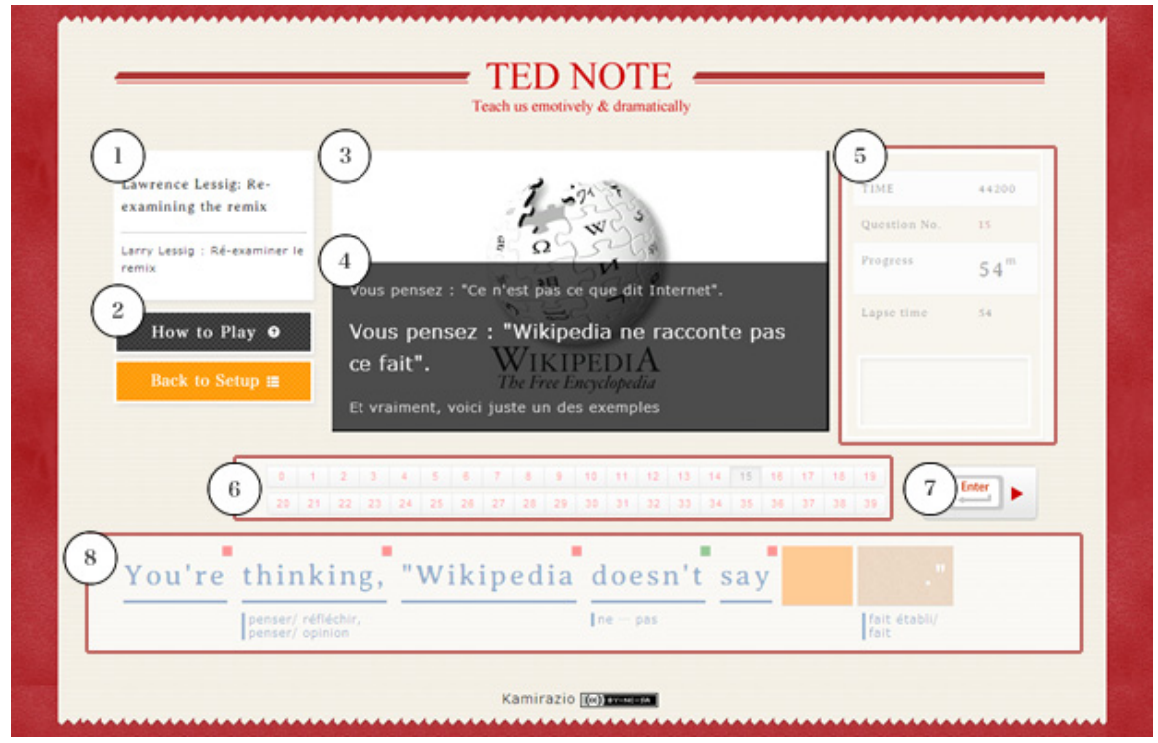

Fig. 4. Home screen: Game interface

Score System. If user completes the typing without any err, user gets high score. The each vocabulary classified 3 levels; junior high, high school and business level. User get additional points depend on the difficulty of each vocabulary. The achievement of user's study habit has been visualized as a total score.

Game Modes. TED NOTE has 3 Game modes.

- typing game mode

Typing the same letters of each word-card

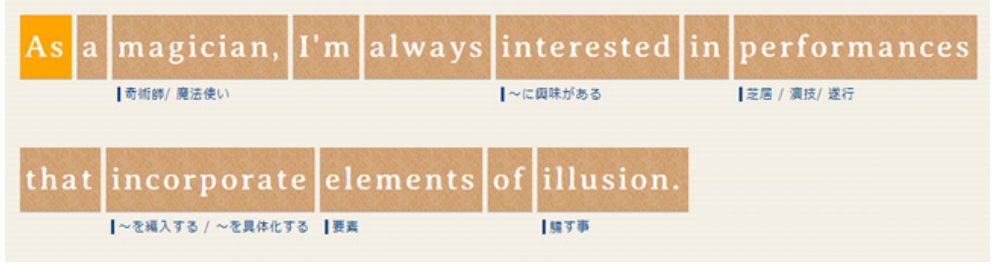

Fig. 5. Typing Game Mode 
- Blank game mode

Filling in the blank question with right letters

Some of the words are selected as blank question randomly.

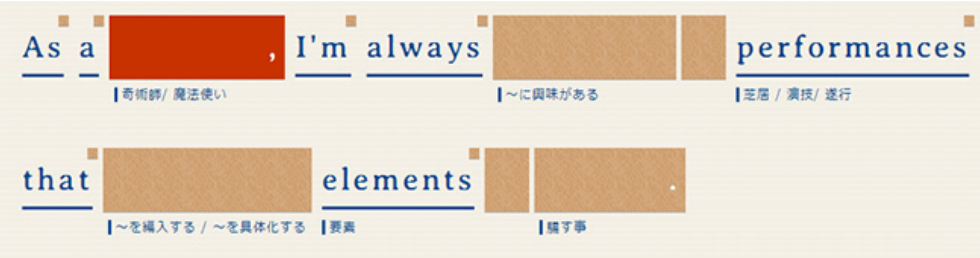

Fig. 6. Blank Game Mode

- Full listening game mode

Filling in all blank questions with the right letters

Most of the words are hidden instead of some difficult words to catch.

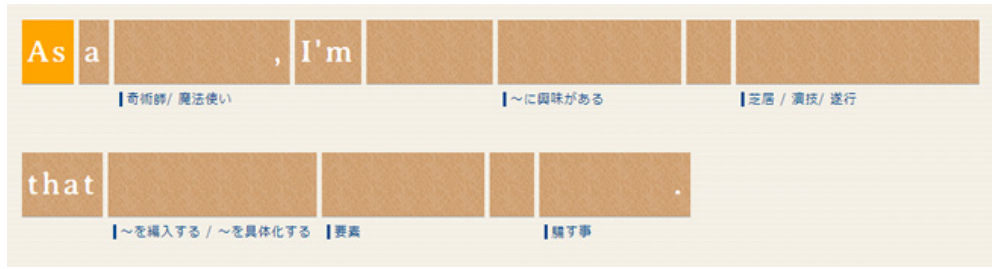

Fig. 7. Full Listening Game Mode

\section{How to Play}

1. Login with own user account from the top page of TED NOTE. (www.connolab.com/tednote/)

2. Choose study mode among 3 options; Typing game mode, Blank game mode and Full listening game mode.

3. Customize your study style with assistant options.

4. Enter the URL of your favorite presentation from TED.com in the URL input box of TED NOTE and press the "Next" Button.

5. After the video has loaded into main interface and questions are generated below, game starts.

6. The video is stopped automatically at the each end of the presenter's statement.

7. Type the same letters, which you can catch from the statement. Repeat and keep listening till user completes each question.

As user can find the correct answer easily, the subtitle and hints are shown below in each word card. You can cheat the answer easily with right and left keys.

8. After user complete the question, press "Space" key to move on to the next question. 


\section{Feedback}

We took user-testing with the first prototype and got the feedback from 4 categorized users; Japanese without international experiences, Japanese who have international experiences, international foreigners and English teachers. From the feedback, we got a lot of opinion. We put some represents below.

\section{Positive Opinions}

- TED NOTE has a possibility to reduce the time to prepare the educational materials for English teachers.

- Not only for students, TED NOTE helps also non-native English teachers to improve their English skills.

- Qualified contents from TED.com will be a good motivation to use TED NOTE better than the traditional way of English study based on textbook or non-native English teachers.

- Design of input layout with keyboard is simple and user-friendly.

- If they use the subtitle and dictionary in second foreign language, it is possible to learn it too at the same time.

\section{Negative Opinions}

- Since we use the subtitle created by the way of user generated contents, each has different quality. Therefore, we found some bugs during the game; the answer wasn't matched to the statement and the vice of presenter wasn't synchronized with the game.

- Users tend to concentrate typing too much to pay attention to the meaning of the presentation.

- The game need more fancy interaction and rewards.

Requests from Users. We go a lot of user request and suggestion of new ideas. Most of users suggested the necessity of SNS function to encourage their continued learning activity. From English teachers, we got some interesting requests. Some asked editing function of the question part customized for student's level. One asked the function of generator, which help to upload his own lecture-video for his own classes.

Finally, based on users' feedbacks, we found that the main target of TED NOTE is middle to advanced class of Japanese English learners, who want to become active worldwide in the future.

\section{Conclusion and Future Prospects}

In this paper, we have discussed how to re-utilize the open content for educational use to get the best benefit of free culture movement. 
Proposing new approaches to designers and engineers, we illustrate our design process of the TED NOTE; the way to re-design the application and the way to re-assembly the system with utilizing open-information resources. Through the development, we found that the approached are more efficient and rapid way to develop application.

We believe that we have succeeded in developing a working prototype, which shows the one of the challenging case study based on free culture movement. However, the current systems haven't realized two more core functions, which we had planned at the first drawing of the system design. As the future improvements, we will install them; SNS function and user generated assignment editor (UGC function.) Additionally, as an e-learning research, we'd like to analyze users' long-term learning effect by monitoring records of self-study management system.

\section{References}

1. Lessig, L.: Free Culture: How Big Media Uses Technology and the Law to Lock Down Culture and Control Creativity, Japan, pp. 328-332 (July 2004)

2. Chen, D.: The guidebook for building a free culture, Japan, pp. 157-169 (May 2012)

3. About Khan Academy (2013), https : / /www . khanacademy . org/about/

4. One Laptop per Child : Open source vs. dual-boot systems Wikipedia, http://en.wikipedia.org/wiki/One_Laptop_per_Child

5. Mitra, S.: Minimally invasive education: a progress report on the hole-in-the-wall. experiments. British Journal of Educational Technology 34, 367 (2003)

6. Rubenstein, L.D.: Using TED Talks to Inspire Thoughtful Practice (2012) ISSN 0887-8730

7. Nikka (Union of Japanese Scientists and Engineers) Practicing Persona Method to Clarify the Target User - Investigating Utilization of a Blog Service for Communities - (2006) 